\title{
Saudi Special Educators' Perceptions of Applied Behavior Analysis for Students with Autism
}

\author{
Hajar Almutlaq,** \\ ${ }^{1}$ College of Education, Majmaah University, Majmaah, Riyadh, Saudi Arabia \\ *Correspondence: College of Education, Majmaah University, Majmaah, Riyadh, Saudi Arabia. Tel: \\ 966-16-404-4444. E-mail: h.almutlaq@mu.edu.sa
}

Received: June 13, 2021

Accepted: August 8, $2021 \quad$ Online Published: August 18, 2021

doi:10.5430/wje.v11n4p18

URL: https://doi.org/10.5430/wje.v11n4p18

\begin{abstract}
Students with disabilities, especially those with Autism Spectrum Disorder, are more likely to display problem behaviors in the classroom for a variety of reasons. Applied Behavior Analysis is one of the most effective practices for managing such behaviors. This study aims to examine special education teachers' perspectives of behavior management strategies such as those of ABA in Saudi Arabia. Five special education teachers teaching students with autism in Saudi Arabia were interviewed to ascertain their perspectives on behavior management strategies and Applied Behavior Analysis practices. This qualitative study investigated the challenges they faced coping with students with autism exhibiting problem behaviors and their understanding of the most common strategies used for behavior management. Finally, the study discusses the understanding of one of the most effective evidence-based practices - Applied Behavior Analysis - and the insight it provides into in-service teacher support programs from the teachers' perspectives. Implications and directions for future research are provided as well.
\end{abstract}

Keywords: special education teachers' perceptions, applied behavior analysis, students with autism, problem behaviors, behavioral interventions

\section{Introduction}

Over the past half century, several special education services have emerged for people with disabilities in Saudi Arabia, and the field of special education is continuing to evolve each year. Yet, few studies focus on this field in Saudi Arabia, especially in the area of Applied Behavior Analysis (ABA) strategies among teachers of students diagnosed with Autism Spectrum Disorder (ASD) (Alotaibi, 2015; Haimour \& Obaidat, 2013). Current studies indicate that teachers in Saudi Arabia lack sufficient ABA knowledge due to inadequate training (Alotaibi, 2015; Haimour \& Obaidat, 2013). ABA strategies are widely utilized as behavioral interventions for students with autism (Cooper, Heron, \& Heward, 2020; Lindgren \& Doobay, 2011). ASD is the broad term for a developmental disorder that affects cognition, and it often emerges between the ages of 18 months and three years (Speaks, 2021).

\subsection{Autism Spectrum Disorder}

Among the 13 disability categories defined under the Individuals with Disabilities Education Act (IDEA) (2004), ASD is reported as one of the most common worldwide. According to the National Center for Education Statistics, it was considered the third most common disability in the United States in 2013 (NCES, 2016). In Saudi Arabia, it is considered the fifth most common disability among students in public schools (Alquraini, 2013). In the last decade, ASD has received national and global recognition in Saudi Arabia. Educators have started to realize the unique strengths and weaknesses of students with autism. For generations, professionals have struggled to find appropriate ways to deal with the problem behaviors of students with autism in the classroom. There are many reasons behind such behaviors, one of them being unpredictable environmental changes. For example, some with autism find it difficult to transition from one activity to another and from one setting to another within their home, school, workplace, and community (Hume et al., 2014). Around 25\% students struggle with transitions occurring during a school day (Koyama \& Wang, 2011; Sainato et al., 1987). When students struggle, they express their discomfort through crying, kicking, or hitting. Thus, the transition process may cause students with autism to act inappropriately during a school day. This makes it hard for special education teachers who teach such students to predict and then 
manage their problem behaviors in the classroom, which can disrupt the learning process and put immense pressure on teachers and peers (Westling, 2010) the disruption is due to teachers and peers paying more attention to these behaviors.

\subsection{Applied Behavior Analysis}

Some special education teachers may fail to implement successful behavioral interventions, such as ABA practices. Kacurovski (2009) found a significant level of unawareness of one of the most important treatment ABA practices among special education teachers. ABA refers to scientific practices to study the behaviors of humans and animals by paying careful attention to the social validity of concerns in addressed and related outcomes (Wolf, 1978). These practices include data collection, observations, development of individualized strategies, and evaluation of the implemented strategy. ABA supports an individual's behavior in six different ways: (1) teaching new skills, (2) increasing appropriate behaviors, (3) maintaining behaviors, (4) changing or replacing responses, (5) decreasing inappropriate behaviors, and (6) generalizing or transferring behavior from one situation to another (Speaks, 2021). While previous studies have investigated appropriate practices for students with autism, there is no a single intervention can work for all such students; even though ABA demonstrates more than three decades of strong empirical evidence and efficacy in their education (Lindgren \& Doobay, 2011). Other studies have shown that ABA strategies help teachers collect accurate data on their students, which then enables them to design an appropriate intervention for a target behavior, eventually. Thus, ABA strategies arm teachers with more skills to manage problem behaviors of students with autism (Gresham et al., 2004). It is possible that the reason special education teachers may fail to implement ABA strategies (Kacurovski, 2009) is because of the existing gap between research and practice (Burns \& Ysseldyke, 2008); some of them may have heard about ABA but not engaged in it practically in a professional setting. In addition to a research-to-practice gap, Burns and Ysseldyke (2008) found that teachers lack support in schools. Special education teachers need adequate support from schools to gain appropriate knowledge and experiences of different evidence-based practice approaches, including ABA strategies. Most special education teachers who graduate from colleges or universities receive minimal training in evidence-based approaches to handle students with autism (The National Research Council, 2001). The researcher predicts an increase in the demand for teachers who are experts in ABA due to the rising number of public school students being diagnosed with ASD (Lerman et al., 2004). Training teachers in the principles and procedures of ABA is challenging because such training involves both academic knowledge of ABA and development of proficiency in actual implementation (Granpeesheh et al., 2010; Schloss \& Smith, 1998). Thus, it is this lack of training and preparation that likely discourages special education teachers from implementing an ABA strategy (Schloss \& Smith, 1998; Khaleel, 2019).

\section{Literature Review}

The education system in the Kingdom of Saudi Arabia (KSA) recently integrated students with disabilities into the general education setting, setting up special education classrooms in every public school. In other words, teaching students with disabilities is no longer limited to the special institutions, which are designed mainly to provide educational services, based on individual disability and needs. Now, the general education classroom in Saudi Arabia includes approximately $10 \%$ students with disabilities. However, around $5 \%$ of diagnosed students have not received appropriate special education services (Alquraini, 2013). It should be noted that Saudi Arabia has passed legislation similar to the United States' 1975 Education for All Handicapped Children (Bin Battal, 2016). In the case of United States, over 10 years later in 1986, 70\% of children in the country had still not received appropriate special education services (Fantuzzo \& Atkins, 1992). Similarly, a high percentage of Saudi students qualify for these services, but they have not received any support due to limited special education resources in the country (Alquraini, 2013). Such resources may include but not be limited to well-qualified teachers, special curriculum based on individual needs, and a prepared and effective learning environment.

When students exhibit challenging behaviors in the classroom, it negatively impacts the learning process (Westling, 2010); peers do not get a fair chance to learn, and teachers' time is taken up trying to manage the challenging behaviors. All students have the right to receive appropriate education, including students with disabilities; and better education can be delivered through well-trained teachers. In the United States, as per the No Child Left Behind Act (2002) and IDEA (2004), special education teachers must be highly qualified. Similarly, Saudi Arabia is now focusing on teacher qualifications. Special education teachers need appropriate preparation to effectively serve students exhibiting challenging behaviors. Due to lack of communication between higher education authorities and the state department of education, many teachers have not received the necessary practical experience, resulting in schools in Saudi Arabia hiring incompetent special education teachers (Sheaha, 2002); colleges in the country tend to 
disseminate a huge amount of academic information with minimum practical experience for aspiring teachers-for example, three and a half years just to acquire ethical information, but only one semester to gain practical experience (Majmaah University, 2021). Such a short duration for practice is insufficient to prepare future teachers. Furthermore, insufficient preparation may lead to job dissatisfaction and other issues, leading to burnout among special education teachers in Saudi Arabia, forcing them to and quit their special education career (Sheaha, 2002). Other findings indicate the need for professional development training for special education teachers in Saudi Arabia (Alotaibi, 2015; Haimour \& Obaidat, 2013; Westling, 2010). Westling (2010) indicated that such teachers need access to both pre-service and in-service training, which would likely enhance their skills for addressing challenging behaviors.

Makrygianni, Gena, Katoudi and Galanis (2018) provided meta-analysis to examine the effectiveness of different ABA practices and they reviewed 29 experimental studies from 1987 to 2017 with a total sample of 831 children who diagnosed with autism. They found that ABA practices were highly effective in improving a variety of abilities and skills, such as intellectual ability, expressive and receptive language and commination skills (Makrygianni, Gena, Katoudi \& Galanis, 2018). In the Arabic region, a study conducted on Zarqa, Jordan, to assess the significant of ABA practices from perspective of teachers. The sample included 120 special education teachers in private schools who teach students with ASD. A statistically significant difference in the result was found in total degrees of importance of using a variety of ABA practices among the participants due to receiving training previously (Khaleel, 2019). ABA practices found to be effective in improving students with ASD abilities and skills (Cooper et al., 2020; Khaleel, 2019; Makrygianni et al., 2018).

Teachers and special education teachers (Khaleel, 2019) believe in the importance of data collection, but they may fail to employ their findings from it in designing appropriate behavior strategies for an individual student (Westling, 2010). The behavior management strategies that special education teachers in Saudi Arabia tend to implement include punishment and time out (Alotaibi, 2015). However, according to Cooper et al. (2020), to maintain successful strategies, some negative ones such as punishment should be avoided or employed only as a last resort. Teachers in Saudi Arabia rarely employ positive behavioral strategies such as positive reinforcement, preferred activity, prompting, and fading (Alotaibi, 2015; Randazzo, 2011). Special education teachers may be aware of effective instructional methods such as observing others who are implementing ABA strategies, reviewing case studies, watching and reflecting on videotapes, listening to lectures, and receiving feedback, and collecting data (Khaleel, 2019) but they still need a guide and foundation to start with (Alotaibi, 2015; Khaleel, 2019). However, educators may fail to implement some of ABA practices correctly such as consistently implementing trial-based instruction teaching (Kodak, Cariveau, LeBlanc, Mahon \& Carroll, 2018). Unfortunately, there are few ABA experts in Saudi Arabia, which impacts implementation of effective behavioral instructional practices (CFAR, 2021). Moreover, in Saudi Arabia, ABA practices have not yet been officially embedded in the special education system; they are limited and employed only by a few private clinics such as the Center for Autism Research (CFAR) in Riyadh (CFAR, 2021).

\subsection{Research Purpose}

Few studies have examined the strengths and weaknesses of strategies that special education teachers in Saudi Arabia, who are teaching students with autism, employ to cope with problem student behaviors in the classroom. Therefore, the present study aims to fill the gap in the literature by examining special education teachers' perspectives of behavior management strategies such as those of ABA in Saudi Arabia. To that end, there is a need to develop an in-depth understanding of such strategies that teachers currently employ to manage students with autism. ABA and interventions derived from behavioral principles have successfully proved to be effective in supporting students with autism (Lindgren \& Doobay, 2011). Also, ABA strategies help teachers to collect accurate data on their students leading to develop an appropriate intervention for a target behavior (Gresham et al., 2004).

\subsection{Research Questions}

Five special education teachers of students with autism in integrated schools and daycare centers participated in semi-structured interviews. This study addresses the following questions.

1. How do special education teachers in Saudi Arabia who are teaching students with autism in an integrated school or a daycare center perceive and experience students' problem behaviors?

2. How do ASD-focused special educators describe other factors that may influence behaviors of students with autism in the classroom, such as instructions and the classroom structure?

3. How do special education teachers in Saudi Arabia who are teaching students with autism in an integrated school or a daycare center describe ABA strategies? 
4. Do ASD-focused special educators have suggestions that may help special education teachers in Saudi Arabia who are teaching students with autism in an integrated school or a daycare center improve their behavior management strategies?

\section{Method}

\subsection{Research Design}

A qualitative case study design was used to provide an in-depth understanding and for exploration of a single case (Creswell \& Poth, 2018). One of the features of case study is that its scope is bounded, which means a case can be defined or described only within certain parameters (Creswell \& Poth, 2018). The case study design provides relevant information to meet the study purpose - this type is called descriptive, used to describe an intervention or phenomenon occurring in a real-life context (Yin, 2003). With respect to the present research, a qualitative case study was conducted with an emphasis on the experiences of a specific population of Saudi special education teachers who teach students with autism in integrated schools and daycare centers and using a case study design was an appropriate to answer the descriptive research questions (Yin, 2003) in this study. Therefore, this study highlighted the teachers' perspectives of behavior management strategies, especially those of ABA. The case study design allowed establishing a certain boundary of this study. For example, the integrated schools and daycare centers the researcher chose have model classrooms, which are designed based on certain standards to ensure that they are appropriate environments to teach students with autism. These classrooms set the boundary of this study, making it unique.

\subsection{Sampling and Participants}

The criterion purposeful sampling approach was employed because it involves selecting those cases that meet some criterion, and it is "useful quality assurance" (Creswell \& Poth, 2018) - this approach was employed to identify and then understand information-rich cases. The design included a certain contextual criterion for the study participants: (1) special education teachers, (2) currently teach students with autism, (3) have more than three years' experience, (4) teach in integrated schools (a public school with autism classrooms), and (5) teach in schools that are in the center of Saudi Arabia where the majority of schools and professional daycare centers for ASD are located.

This study had five participants working in different schools and daycare centers. Table 1 contains more details about the participants, who volunteered for a one-on-one interview to describe their experiences. Pseudonyms have been used to protect their identity.

Table 1. Participant Details

\begin{tabular}{|c|c|c|c|c|}
\hline Participants & Gender & Job & Years of experience & Workplace/Expertise \\
\hline Abdual & Male & $\begin{array}{l}\text { Special education } \\
\text { teacher and counselor }\end{array}$ & 7 years and 3 months & $\begin{array}{l}\text { Integrated school/Behavioral disorder } \\
\text { and ASD }\end{array}$ \\
\hline Manar & Female & $\begin{array}{lr}\text { Special } & \text { education } \\
\text { teacher } & \text { and } \\
\text { home-based } & \text { services } \\
\text { provider } & \end{array}$ & 8 years and 10 months & $\begin{array}{l}\text { Daycare center/Behavioral disorder and } \\
\text { ASD }\end{array}$ \\
\hline Amal & Female & $\begin{array}{l}\text { Special } \\
\text { teacher }\end{array}$ & 4 years & $\begin{array}{l}\text { Daycare center/Behavioral disorder and } \\
\text { ASD }\end{array}$ \\
\hline Reham & Female & $\begin{array}{l}\text { Special education } \\
\text { teacher and school } \\
\text { principal }\end{array}$ & 3 years and 6 months & $\begin{array}{l}\text { Daycare center/Behavioral disorder and } \\
\text { ASD }\end{array}$ \\
\hline Ahmad & Male & $\begin{array}{l}\text { Special } \\
\text { teacher }\end{array}$ & 4 years and 2 months & $\begin{array}{l}\text { Integrated school/Behavioral disorder } \\
\text { and ASD }\end{array}$ \\
\hline
\end{tabular}




\subsection{Procedure}

\subsubsection{Ethical Considerations}

A consent form and the researcher's questions were provided to each participant prior to the meeting time, and they all agreed to participate in this study. They were informed that they had the option of declining to answer or passing on any of the questions.

\subsubsection{Interviews}

The participants were asked to meet the researcher for a semi-structured interview session. The questions were general and abstract, and the participants were informed that they may volunteer additional details. Because the participants expressed that they were more comfortable with phone interviews, the researcher interviewed them over call. The average length of the interviews was 46 minutes. Abdual and Manar were interviewed on February 2, 2020 - his interview lasted for 52 minutes and hers for 51 minutes. Amal was interviewed on February 10, 2020, and that interview lasted for 35 minutes. Reham and Ahmad were interviewed on February 13, 2020 - her interview lasted for 45 minutes and his for 35 minutes. The participants were asked to evaluate the performance of their colleagues. For example, one of the questions was "Tell me more about how your colleagues deal with problem student behaviors." They were asked to provide suggestions to raise awareness of ABA strategies among special education teachers. They provided valuable suggestions, which will inform the development of future studies. All the interviews were audio recorded, transcribed, and then sent to the participants for member checks to ascertain if the transcripts accurately conveyed their meaning.

\section{Data Analysis}

The qualitative data was analyzed using inductive analysis, by employing comparison, contrast, aggregating, and ordering strategies (LeCompte \& Preissle, 1993; Shank, 2002). These strategies were used to review and organize the data to search for themes within, which could then be used to answer the research questions. The different strategies used based on guidelines set by LeCompte and Preissle (1993) and Shank (2002) directed how to order and analyze the data to best meet the study purpose. Inductive analysis was carried out to provide specific information needed to answer the research questions.

First, the researcher typed out the transcript in MS Word for each participant, and then transferred the data to an Excel document in a way that facilitated a comparison and contrast between the participants' responses. Then, each participant's data was cut and clustered in a different Word document based on segmenting criteria. Each segment was tied to the respective research question; thus, this study has 13 segments. Once the segmentation was done, the transcripts were coded line by line and a table created in another Word document. The researcher copied and pasted the codes in the document while grouping them based on similar content/patterns. Also, the frequency of similar content within or across participants was recorded. Codes were then compared and contrasted through incident comparison and theoretical comparison across the data (Shank, 2002) using the Excel document. The major patterns were then converged into categories. Eight major categories, considered as important variables (Shank, 2002), were arrived at: (a) Describing Teaching Students with Autism, (b) Describing Problem Behaviors, (c) Other Factors that Influence Problem Behaviors, (d) Current Management Strategies, (e) Essential Elements for Successful Behavioral Interventions, (f) ABA, (g) Teacher Support, and (h) Teachers' Suggestions. Sub-codes were added as necessary to provide details about each category, such as Preparations, Beliefs, and Environmental Factors. Code examples provided in Table 2 of the codebook are in the Appendix A. Categories showed the causal relationship and logical chain of evidence, which helped shed light on the phenomenon. Then, a comparison and contrast of the important variables, metaphors, and themes across all segments was undertaken to build a comprehensive map of the target phenomenon (Shank, 2002). After theorizing established linkages and relationships across segments and themes, linkages and relationships were explained to clarify why these connections exist in this study. The researcher used theorizing to construct explanations best fitting the data (Morse, 1994).

\subsection{Trustworthiness}

In the beginning of this study, there was an attempt to establish trustworthiness throughout the study. The researcher adopted the post-positivist epistemological stance owing to the belief that perfect objectivity cannot be reached fully but is approachable.

The attempt to ensure an objective study and capture participant perspectives of a specific phenomenon was initiated prior to implementing the study. Thus, conformability was achieved, with the findings based on participant responses. 
Moreover, other qualitative research practices were found to be useful to capture these responses objectively, such as memo-writing, which was implemented during the data collection and analysis stages. A graduate student assisted to check the accuracy of transcription, translation, and data analysis. A copy of the transcript was sent for each participant to ensure accurately conveyed their meaning.

\section{Findings and Discussion}

The findings of this study answer the research questions in various ways. This section addresses the research questions consecutively; the original data was translated from Arabic to English by the researcher, as the participants defined themselves as non-speakers of the English language. From the research questions, four themes emerged - the teachers' descriptions of teachers' experiences with students with autism, teachers' descriptions of other factors that may influence such students, teachers' descriptions of ABA, and teachers' suggestions.

\subsection{Research Question 1: Teachers' Experiences with Students with Autism}

The participants described different experiences when dealing with students with autism. Their experiences were based on their values, beliefs, and other personal skills. For example, Manar, who has over eight years' experience teaching students with autism, gave an example of how beliefs and training may make a difference when teaching these students:

It's easy for someone who is well trained to work with these students, and it would definitely be hard for a new teacher or someone who has no experience. For example, some new teachers have said that these students are disabled, and no matter how much effort goes into teaching them, it's not going to help them at all. I believe that we first need to understand them and then help them. If there is mandatory in-service training for all teachers, it would be easier for those teaching students with autism.

Amal, who has 4 years' experience, looked at it from a different angle, saying the teacher's responsibilities extended beyond the teaching process:

It is hard, not everyone can teach them. This job needs someone who is honest and dedicated to the work. It is a huge responsibility to teach these kids; I'm also responsible for taking them to the restroom, as well as feeding and protecting them. Not everyone can deal with these kids because they are too dependent on the teacher, and the teacher is responsible for everything.

These findings describing the general process of teaching students with autism from teacher perspectives are consistent with those of the study by Helps et al. (1999), who discovered the many difficulties teachers face when teaching students with autism. These include cognitive difficulties similar to what Manar shared, which is that some teachers believe that "most children with autism are intellectually disabled." This shows that they believe that there is no benefit in attempting to teach these students. These findings also reveal communication difficulties between students and teachers, which are considered one of the typical symptoms students with autism have (Speaks, 2021); and such difficulties can cause miscommunication between the two parties. This may place teachers under great stress in trying to figure out what students may need (Westling, 2010).

\subsubsection{Describing Problem Behaviors}

Teachers face difficulties when they are dealing with problem student behaviors (Westling, 2010). Aggression, hitting, crying, and screaming were the most common inappropriate behaviors the participants reported. Amal, Reham, and Ahmad agreed that students usually exhibit problem behaviors because of students' lack of ability to communicate and interact with the environment around them. Amal explained some of the inappropriate behaviors students with autism might display:

I see aggressive behaviors toward themselves or others. It can be a common inappropriate behavior by students with autism. What are the reasons causing these inappropriate behaviors do you think? I think the kid wants something; he/she cannot express his/her feelings or needs, and as a result, might exhibit inappropriate behaviors. Can you give an example? Yes. When the child is hungry or wants to go to the restroom but cannot communicate, he/she starts to make trouble to get what he/she wants. Often, kids do not get enough sleep, or they sleep late, and when they arrive at the center, they don't respond appropriately and start distracting their peers. They thus start to show aggressive behaviors.

Amal mentioned aggressiveness as the most common inappropriate behavior she witnessed among students with autism. She realized that such students might start acting out when they fail to communicate their needs. 
Manar and Abdual had a different interpretation of what caused problem behaviors among such students - transition issues or trouble accepting sudden changes in their routine. Manar discussed how the transition from home to school influenced student behaviors and feelings:

Kids are sitting on their chairs inside the classroom, and they are not aware why they are in a classroom or at school, especially when they have recently transitioned from home to school. So, they may react negatively toward themselves or others, because they are scared or uncomfortable being in a place that is different from their homes.

Abdual explained some of the transition issues and unpredictable changes that were difficult for students with autism to accept: "If there is a new teacher, these students will not easily accept this change. Or if we have to change their classroom..." Students with autism are facing difficulty transitioning from one activity to another during a school day. This is consistent with what Hume et al. (2014) found regarding how such students struggle when they transition from one activity to another and from one setting to another within their home, school, workplace, and community.

Moreover, Reham believed that the sensory sensitivity many students with autism have might cause them to exhibit inappropriate behaviors in the classroom. She described how having high sensory sensitivity may push some of them to cry or yell to express their discomfort. The majority of resources that discussed ASD symptoms stated that sensory sensitivity is not a core symptom, but it could be a common issue among some individuals with autism (Speaks, 2021; CFAR, 2021). However, the researcher believes that teachers may be able to control some of the potential output in the classroom environment that may trigger students' sensitivities, which may prevent problem behaviors from occurring and, therefore, create a comfortable classroom environment for the students, peers, and teachers.

\subsubsection{Current Management Strategies}

Teachers have a responsibility to manage problem student behaviors in the classroom. The study participants reported that they use behavior management strategies to deal with such behaviors. These strategies include ignoring, modeling, and verbal prompts. Teachers tend to model the skills by verbalizing their thinking at each step to help students follow, and provide physical assistance along with it if needed. For example, Manar said that she often uses a modeling strategy to manage problem student behaviors: "I use modeling to inform the kids about the problem. If I find the cause of each problem, it would be easy to deal with them." This is consistent with what Khaleel (2019) found that modeling was the most significant ABA practices that special education teacher's favor.

Finding out the trigger causing a problem behavior for help in fixing it is a very important piece of information that Manar shared. When a teacher is able to determine the function of problem behaviors, it will save time and effort in developing strategies to prevent a problem behavior from occurring. Interestingly, Khaleel (2019) found that female teachers were highly rating the significant of collecting data on a student problem behavior, despite; gender was not a major focus in this study.

However, some of the participants tended to use punishment as the first management strategy. Abdual mentioned that he used two strategies for most problem behaviors students exhibited in the classroom, adding that these work most of the time: "I usually follow two procedures: 1) take off a token and 2) send the child to the thinking area. Guess what? They work most of the time and prevent problem student behaviors." Abdual used what is called punishment strategies based on ABA, and these proved to be less effective than those the other participants tended to use, such as modeling and verbal prompts. In fact, Khaleel (2019) found that male teachers tend to favor punishment strategies more than female teachers. On the other hand, a pattern emerged across participants where they all agreed that ABA strategies were effective for managing problem behaviors in students with autism. Moreover, Reham and Ahmad agreed that the majority of teachers they worked with used punishment as the main strategy to manage problem student behaviors.

Generally, it is often recommended to begin with a number of reinforcing strategies before resorting to punishment, and a punishment strategy should only be employed in specific situations while considering particular standards (Cooper et al., 2020). The predicted lack of knowledge about effective behavior management strategies appeared to push the participants to use punishment as the first and an easy strategy to manage similar cases. Thus, to answer the first research question based on the data provided, the participants described teaching students with autism as a difficult process due to lack of practical knowledge. Also, they tended to employ less effective behavioral interventions to manage problem student behaviors.

\subsection{Research Question 2: Other Factors That Influence Problem Behaviors}

The participants agreed that there are other factors not related to student cognitive processes that may influence their behavior in the classroom. An unorganized classroom environment may influence some students to exhibit inappropriate behavior. Amal and Reham discussed the influence of classroom organization, which showed the 
relationship between environmental factors and student behaviors. In fact, Amal acknowledged, "The classroom structure and organization can affect student behaviors. For example, the autism classroom should be free of distracting materials because kids with autism can get distracted easily by many objects around them."

Other participants mentioned other factors such as teacher preparation and classroom preparation, classroom location, and having visitors in the classroom. Also, transition issues and unpredictable changes discussed earlier (Hume et al., 2014) were the other environmental factors negatively impacting student behaviors; however, the participants described some environmental factors that helped students maintain appropriate behaviors in the classroom, including following a consistent daily schedule, dividing students into groups based on similar needs, and providing students with certain non-challenging responsibilities. When teachers are able to identify potential relationships between environmental factors and student behaviors, it can strengthen their behavior management skills - the researcher assumes that determining these relationships could possibly help teachers predict what may cause students to act out and then manipulate the classroom environment, to reduce problem student behaviors.

\subsection{Research Question 3: ABA}

ABA refers to scientific practices to study the behaviors of humans and animals by paying careful attention to the social validity of concerns in addressed and related outcomes (Wolf, 1978). Studies have reported about teachers' lack of knowledge of ABA (Alotaibi, 2015; Haimour \& Obaidat, 2013; Westling, 2010). In this study, the participants said that they had some knowledge of ABA. Reham and Ahmad mentioned that they are conducting other programs rather than ABA, such as APPLE, HELP_POP, and Lovaas, which were recommended by their school district. There was not sufficient information about APPLE and HELP-POP in both Arabic and English languages, but the participants claimed that these were associated with some of the ABA principles. Only Lovaas uses discrete trials training, which is considered an ABA strategy (Cooper et al., 2020; Lovaas, 1987). The researcher assumes that use of one ABA strategy is not sufficient to judge a program's effectiveness.

Abdual and Amal said that they have been employing ABA strategies on a daily basis. For example, Abdual provided a description that was very similar to ABA strategies: "I think we need to observe the behavior, and then, we start drawing a baseline." He briefly described a routine procedure, which is representative of an essential part of ABA. According to Wolf (1978), ABA refers to scientific practices that include data collection, observations, and evaluation of the implemented strategy. This indicates that Abdual probably has some basic knowledge of ABA. Also, Amal described ABA as a way to change a student's behaviors: "If there is a behavior we want to change, we need to work on it once or longer until it has changed. We need to give the child a chance to fix that behavior."

Though both Abdual and Amal displayed a little knowledge of ABA, theirs is considered an insufficient description of it. On the other hand, Manar made the association between the success of ABA strategies and time spent: "I taught him [a student with autism] many skills such as living skills, independent living skills, and how to take care of himself. After spending a certain number of hours, I saw an improvement in him. The more time I spent with him, the more improvement I saw."

However, more is needed than solely spending more time with students to achieve certain goals. Each intervention should be structured to address specific student needs and expectations. Regarding time, research shows that an estimated 10 to 15 intervention hours per week are needed with a child for noticeable improvement (Lovaas, 1987).

A pattern detected across participants showed that they did not feel sufficiently prepared to implement ABA strategies, and that they were seeking more professional development. This pattern was also seen in participant responses reporting that their colleagues were not prepared to implement ABA strategies. Most of the responses indicated that the participants had misconceptions about ABA strategies and needed additional training in this area. For example, Abdual said, "I would not try to implement an ABA strategy with little knowledge of this field." Manar mentioned, "I'm not really good at it," regarding her preparedness to implement ABA strategies.

During the interviews, the researcher asked the participants how they learned about ABA, and all said that they had taken it as a college course that focused primarily on behavior management. For example, Manar described her experience of learning about $\mathrm{ABA}$ in college, saying she has had more opportunity to practice since starting this job: "I learned about ABA in college, but it was dry knowledge. I've started practicing some ABA strategies now with my students." She as well as the other participants indicated that learning about ABA in college was not sufficient, and that in-service training was required-Abdual, for example, insisted that it was necessary to gain more professional development support:

We do lack information and, for sure, need direct training (live training) in the classroom to be able to practice and master ABA strategies. Eventually, we need an actual opportunity... not simply receive auditory information. Google 
is filled with written information, and we need someone who is a specialist to direct us in real situations.

Some school districts offer workshops for teachers in behavior management strategies including those of ABA; however, Amal, Abdul, Reham, and Ahmad mentioned that most workshops are given by presenters neither specialized in special education nor in ABA or related fields. They said that they did not fully benefit from such workshops, and felt unprepared to confidently implement ABA strategies.

These findings answer the third research question-special education teachers in Saudi Arabia consider ABA strategies effective for behavior management of students with autism. However, teachers are lacking in ABA knowledge, and hence, seeking professional development training. This supports results of other studies showing that ABA strategies have strong empirical efficacy (Lindgren \& Doobay, 2011), and that special education teachers have insufficient skills and experiences to confidently implement ABA strategies (Kacurovski, 2009; Khaleel, 2019). Some special education teachers may hear about ABA, but they do not have practical experience of it in a professional setting, and this creates a gap between research and practice (Burns \& Ysseldyke, 2008). Teachers realize the need for more professional development training, and the participants of this study clarified that abstract information provided in lectures or workshops was not sufficient to master behavior management strategies like those of ABA.

\subsection{Research Question 4: Teachers'Support and Suggestions}

Special education teachers who have over three years of experience teaching students with autism are considered a rich resource of information effecting improvements in the education system for both teachers and students. Thus, the researcher decided to ask the participants this research question at the end of the study, to help them develop an idea about what the interview was mainly about, and then, to obtain relatively significant details. Besides asking them for suggestions, the researcher also asked them about their needs to support their knowledge and skills.

Earlier, the participants had admitted the effectiveness of ABA strategies, and suggested that they should receive professional ABA training. Abdual pointed out, "If we are able to manage a student's problem behavior using ABA, other issues would be easy." To clarify his statement, his intended meaning was that if the teacher is able to manage problem student behaviors using ABA strategies, he/she would be able to solve other behavioral or teaching issues with minimum effort. This supports the findings discussing how challenging behaviors disrupt the learning process and put severe pressure on teachers (Westling, 2010), insisting the need of training teachers on ABA practices (Khaleel, 2019). Thus, special education teachers need to be adequately prepared to manage students' problem behaviors through practices such as ABA.

Teachers need available resources to provide them with more information to improve their professional skills. Abdual said that teachers need to have access to a professional program: "Teachers need access to other resources of information, such as the Alternative Communication Program, PECS-The Picture Exchange Communication System." These may provide teachers with guidelines on how to assess, teach, and communicate with students with autism, thus benefiting both teachers and students. Students with autism often have communication issues that lead to problem behaviors. Communication programs preempt such behaviors by providing a way to ensure that students' needs are met (Cafiero \& Meyer, 2008). One of the benefits of using these educational programs, PECS for instance, is facilitating communication between students and teachers-successful communication helps reduce the problem behaviors students exhibit when they feel they are unable to communicate and express their needs. Also, reducing problem behaviors has positive effects by reducing the stress on teachers and peers in the classroom. This is consistent with the findings of Westling (2010), who highlighted that students exhibiting problem behaviors in the classroom disrupted the learning process and put severe pressure on teachers and peers.

\section{Conclusion}

This study contributes valuable information to fill the gap highlighted in the literature review, especially in Saudi Arabia, where special education is still developing. Few studies have evaluated teachers' knowledge of behavior management strategies using specific questionnaires (Burns \& Ysseldyke, 2008; Gresham et al., 2004; Kacurovski, 2009; Schloss \& Smith, 1998; Westling, 2010), while this study presented real experiences informed directly by teachers. Findings from this study may allow teachers, administrators, and others interested in special education to offer additional opportunities to train teachers to effectively manage problem behaviors in students with autism. A deeper understanding of teacher perspectives of such behaviors may provide administrators with valuable information as well as knowledge on the support teachers need. The findings may also allow administrators to consider greater inclusion of the families of students with autism in working with teachers to achieve successful 
behavioral plans.

The final research question asked the participants to provide suggestions for other special education teachers. Their valuable suggestions included facilitating more access to available resources for teachers and providing additional learning opportunities for professional development. For example, all participants agreed that they needed support to effectively employ ABA and other behavior management strategies with students with autism. These suggestions may improve special education by creating comfortable learning environments for both teachers and students.

\subsection{Limitations}

In terms of limitations, the participants declared that they did not have English proficiency, and thus, they were interviewed in their first language, Arabic. The researcher and another specialist then translated the transcripts. There are concerns regarding the translation, about it possibly changing the essential meaning of the participants' words. In addition, interviewing participants via a phone call might result the absence of facial cues in messages, which leads to misunderstanding. The participants, however, were provided with a copy of their transcribed interview to confirm their responses. The sample size was limited in the study. However, the researcher investigated three participants in the first phase, until the collected data reached saturation after added two more participants. Thus, the purpose of this case qualitative study is providing in-depth explanations of a particular practice rather than generalizing findings.

\subsection{Implications and Directions for Future Research}

This study highlighted some of special education teachers' professional needs to effectively manage problem behaviors of students with autism. Future studies should determine the quantity and quality of the support needed. They should also focus on preparing educators with evidence-based practices to manage students' behavioral issues, such as ABA. Current educators are in significant need of professional development to improve their skills.

\section{Acknowledgment}

The author extend her appreciation to the deputyship for Research \& Innovation, Ministry of Education in Saudi Arabia for funding this research work through the project number (IFP-2020-19)

\section{References}

Alotaibi, A. A. (2015). Knowledge and use of applied behavior analysis among teachers of students with Autism Spectrum Disorder in Saudi Arabia [Doctoral thesis, Washington State University].

Alquraini, T. (2013, November 5). Statistical figures and the status of special education in the Kingdom. Al-jazirah. Retrieved from http://www.al-jazirah.com/2013/20131105/rj8.htm

Bin Battal, Z. M. (2016). Special education in Saudi Arabia. International Journal of Technology and Inclusive Education, 5(2), 880-886. https://doi.org/10.20533/ijtie.2047.0533.2016.0113

Burns, M. K., \& Ysseldyke, J. E. (2008). Reported prevalence of evidence-based instructional practices in special education. The Journal of Special Education, 43(1), 3-11. https://doi.org/10.1177/0022466908315563

Cafiero, J. M., \& Meyer, A. (2008). Your child with autism: When is augmentative and alternative communication (AAC) an appropriate option? Exceptional Parent, 38(4), 28-30.

Center for Autism Research. (2021). Applied behavior analysis. Retrieved from https://cfar.kfshrc.edu.sa/ar/Training

Cooper, J. O., Heron, T. E., \& Heward, W. L. (2020). Applied behavior analysis. Pearson, UK.

Creswell, J. W., \& Poth, C. N. (2018). Qualitative inquiry and research design: Choosing among five approaches (4th ed.). Thousand Oaks, CA: Sage.

Fantuzzo, J., \& Atkins, M. (1992). Applied behavior analysis for educators: Teacher centered and classroom based. Journal of Applied Behavior Analysis, 25(1), 37-42. https://doi.org/10.1901/jaba.1992.25-37

Granpeesheh, D., Tarbox, J., Dixon, D. R., Peters, C. A., Thompson, K., \& Kenzer, A. (2010). Evaluation of an eLearning tool for training behavioral therapists in academic knowledge of applied behavior analysis. Research in Autism Spectrum Disorders, 4(1), 11-17. https://doi.org/10.1016/j.rasd.2009.07.004

Gresham, F. M., McIntyre, L. L., Olson-Tinker, H., Dolstra, L., McLaughlin, V., \& Van, M. (2004). Relevance of functional behavioral assessment research for school-based interventions and positive behavioral support. Research in Developmental Disabilities, 25(1), 19-37. https://doi.org/10.1016/j.ridd.2003.04.003 
Haimour, A. I., \& Obaidat, Y. F. (2013). School teachers' knowledge about autism in Saudi Arabia. World Journal of Education, 3(5), 45. https://doi.org/10.5430/wje.v3n5p45

Helps, S., Newsom-Davis, I., \& Callias, M. (1999). Autism: The teacher's view. Autism, 3(3), $287-298$. https://doi.org/10.1177/1362361399003003006

Hume, K., Sreckovic, M., Snyder, K., \& Carnahan, C. R. (2014). Smooth transitions: Helping students with autism spectrum disorder navigate the school day. Teaching Exceptional Children, 47, 35-45. https://doi.org/10.1177/0040059914542794

Individuals with Disabilities Education Act, 20 U.S.C. $§ 1400$ (2004).

Kacurovski, S. (2009). Applied behavior analysis and autism-spectrum disorders (Doctoral thesis). St. John Fisher College] Education Masters.

Khaleel, Y. F. (2019). Assessing the knowledge level of teachers of children with autism spectrum disorder about the importance of applied behavior analysis (ABA) strategies in Zarka city. International Education Studies, 12(5), 120-132. https://doi.org/10.5539/ies.v12n5p120

Kodak, T., Cariveau, T., LeBlanc, B. A., Mahon, J. J., \& Carroll, R. A. (2018). Selection and implementation of skill acquisition programs by special education teachers and staff for students with autism spectrum disorder. Behavior Modification, 42(1), 58-83. https://doi.org/10.1177/0145445517692081

Koyama, T., \& Wang, H. (2011). Use of activity schedule to promote independent performance of individuals with autism and other intellectual disabilities. Research in Developmental Disabilities, 32(6), 2235-2242. https://doi.org/10.1016/j.ridd.2011.05.003

LeCompte, M. D., \& Preissle, J. (1993). Ethnography and qualitative design in educational research (2nd ed.). New York Academic Press.

Lerman, D., Vorndran, C., Addison, L., \& Kuhn, C. (2004). Preparing teachers in evidence-based practices for young children with autism. School Psychology Review, 33, 510-526. https://doi.org/10.1080/02796015.2004.12086265

Lindgren, S., \& Doobay, A. (2011). Evidence-based interventions for autism spectrum disorders. The University of Iowa, Iowa. Retrieved from http://www.interventionsunlimited.com/editoruploads/files/Iowa\%20DHS\%20Autism\%20Interventions\%206-1 0-11.pdf

Lovaas, O. I. (1987). Behavioral treatment and normal educational and intellectual functioning in young autistic children. Journal of Consulting and Clinical Psychology, 55(1), 3. https://doi.org/10.1037/0022-006X.55.1.3

Majmaah University. (2021). The study plan for special education program, college of education, Majmaah university. Retrieved from https://www.mu.edu.sa/sites/default/files/content/2016/02/1_16.pdf

Makrygianni, M. K., Gena, A., Katoudi, S., \& Galanis, P. (2018). The effectiveness of applied behavior analytic interventions for children with Autism Spectrum Disorder: A meta-analytic study. Research in Autism Spectrum Disorders, 51, 18-31. https://doi.org/10.1016/j.rasd.2018.03.006

Morse, J. M. (1994). Designing funded qualitative research. In N. K. Denzin \& Y. S. Lincoln (Eds.), Handbook of qualitative research (p. 220-235). Sage Publications, Inc

National Research Council. (2001). Educating children with autism. Washington, DC: The National Academies Press. https://doi.org/10.17226/10017

Randazzo, M. E. (2011). Elementary teachers' knowledge and implementation of applied behavior analysis techniques (Doctoral thesis). Rutgers University-Graduate School of Applied and Professional Psychology.

Sainato, D. M., Strain, P. S., Lefebvre, D., \& Rapp, N. (1987). Facilitating transition times with handicapped preschool children: A comparison between peer-mediated and antecedent prompt procedures. Journal of Applied Behavior Analysis, 20(3), 285-291. https://doi.org/10.1901/jaba.1987.20-285

Schloss, P., \& Smith, M. (1998). Applied behavior analysis in the classroom. Boston, MA: Allyn and Bacon.

Shank, G. (2002). Qualitative research: A personal skills approach. New Jersey: Merrill Prentice Hall.

Sheaha, M. H. (2002). Factors related to job dissatisfaction among special education teachers in Saudi Arabia (Doctoral thesis). University of Northern Colorado.The Education for All Handicapped Children Act, 42 U.S.C. 
$\S 1983$.

Speaks, A. (2021, August 23). What is autism. Retrieved August, 23, 2021 from https://www.autismspeaks.org/what-autism

U.S. Department of Education, National Center for Education Statistics. (2016). Digest of Education Statistics, 2015 (NCES 2016-014), Chapter 2.

Westling, D. L. (2010). Teachers and challenging behavior: Knowledge, views, and practices. Remedial and Special Education, 31(1), 48-63. https://doi.org/10.1177/0741932508327466

Wolf, M. M. (1978). Social validity: The case for subjective measurement or how applied behavior analysis is finding its heart. Journal of Applied Behavior Analysis, 11, 203-214. https://doi.org/10.1901/jaba.1978.11-203

Yin, R. K. (2003). Case study research: Design and methods. Thousand Oaks, CA: Sage.

\section{Appendix A}

Table 2. Codebook

\begin{tabular}{|c|c|c|c|c|}
\hline Categories & Code examples & Sub-code 1 & Sub-code 2 & Number of responses \\
\hline & - Easy for well-trained teachers & \multirow[t]{2}{*}{ Preparation } & & \multirow[t]{2}{*}{5} \\
\hline Describing Teaching & - Hard, and it needs experience & & & \\
\hline Students with Autism & - Believing in students' abilities & \multirow[t]{2}{*}{ Beliefs } & & \multirow[t]{2}{*}{2} \\
\hline & - Needs patience and dedication & & & \\
\hline Describing Problem & - Exhibiting inappropriate & & & 5 \\
\hline Behaviors & behaviors & & & \\
\hline Other Factors that & - Teachers' preparation & \multirow{2}{*}{$\begin{array}{l}\text { Environmental } \\
\text { factors }\end{array}$} & & \multirow[t]{2}{*}{4} \\
\hline $\begin{array}{l}\text { Influence Problem } \\
\text { Behaviors }\end{array}$ & - Classroom preparation & & & \\
\hline \multirow{3}{*}{$\begin{array}{l}\text { Current Management } \\
\text { Strategies }\end{array}$} & - Molding & \multirow{3}{*}{$\begin{array}{l}\text { Behavioral/ } \\
\text { Teaching }\end{array}$} & Learned & \multirow[t]{3}{*}{5} \\
\hline & - Ignoring & & strategies & \\
\hline & - Verbal prompts & & Colleagues' & \\
\hline \multirow{4}{*}{$\begin{array}{l}\text { Essential Elements for } \\
\text { Successful Behavioral } \\
\text { Interventions }\end{array}$} & & & & \multirow{4}{*}{5} \\
\hline & - Identifying problem behaviors & $\begin{array}{l}\text { Educational } \\
\text { procedures }\end{array}$ & $\begin{array}{l}\text { Teaching } \\
\text { procedures }\end{array}$ & \\
\hline & $\begin{array}{l}\text { - Working collaboratively with } \\
\text { teachers }\end{array}$ & \multirow[t]{2}{*}{$\begin{array}{l}\text { Parents' } \\
\text { involvement }\end{array}$} & & \\
\hline & - Inactive parents & & & \\
\hline \multirow[t]{2}{*}{$\begin{array}{l}\text { Applied Behavior } \\
\text { Analysis (ABA) }\end{array}$} & $\begin{array}{l}\text { - Observing and monitoring the } \\
\text { problem behavior }\end{array}$ & \multirow[t]{2}{*}{ Description } & \multirow[t]{2}{*}{$\begin{array}{l}\text { Teachers' } \\
\text { preparation }\end{array}$} & \multirow[t]{2}{*}{2} \\
\hline & - Task analysis & & & \\
\hline \multirow[t]{3}{*}{$\begin{array}{l}\text { Teachers' Support and } \\
\text { Suggestions }\end{array}$} & - Effective communication skills & $\begin{array}{l}\text { Teachers' } \\
\text { satisfaction }\end{array}$ & & \\
\hline & $\begin{array}{l}\text { - Access to more educational } \\
\text { programs }\end{array}$ & \multirow[t]{2}{*}{ Teachers' needs } & \multirow[t]{2}{*}{$\begin{array}{l}\text { Resources } \\
\text { available }\end{array}$} & \multirow[t]{2}{*}{5} \\
\hline & $\begin{array}{l}\text { - Increasing professional } \\
\text { development opportunities for } \\
\text { teachers }\end{array}$ & & & \\
\hline
\end{tabular}

*Numbers 1-4 indicate themes, defined based on the research questions: 1- Teachers' description of teaching students with autism, 2- Teachers' description of other factors that may influence behaviors of students with autism, 3- Teachers' description of the Applied Behavior Analysis (ABA) practice, and 4- Teachers' suggestions. 


\section{Copyrights}

Copyright for this article is retained by the author(s), with first publication rights granted to the journal.

This is an open-access article distributed under the terms and conditions of the Creative Commons Attribution license (http://creativecommons.org/licenses/by/4.0/). 